\title{
Microsurgery or open cervical foraminotomy for cervical radiculopathy? A systematic review
}

\author{
Zhaojun Song $^{1} \cdot$ Zhi Zhang $^{1,2} \cdot$ Jie Hao $^{1} \cdot$ Jieliang Shen $^{1} \cdot$ Nian Zhou $^{1} \cdot$ Shengxi Xu $^{1}{ }^{1}$ \\ Weidong $\mathrm{Ni}^{1} \cdot$ Zhenming $\mathrm{Hu}^{1}$
}

Received: 28 March 2016/Accepted: 4 April 2016/Published online: 25 April 2016

(C) The Author(s) 2016. This article is published with open access at Springerlink.com

\begin{abstract}
Objective The purpose of this article was to systematically review the clinical outcomes of microendoscopic foraminotomy compared with the traditional open cervical foraminotomy. Methods A literature search of two databases was performed to identify investigations performed in the treatment of cervical foraminotomy with microsurgery or an open approach. Data including blood loss, surgical time, hospital stay, complications, clinical success rate, reduction of arm and neck pain, improvement of neurological function, and repeated surgery rate were summarized, calculated and compared. Results of clinical success were performed by calculattng effect indicators and standard errors based on a single rate to assess heterogeneity in the two groups.

Results The initial literature search resulted in 713 articles, of which, 26 were determined as relevant on abstract review. An open foraminotomy approach was performed in 16 and a microsurgery approach in ten studies. The open group demonstrated minimal to moderate heterogeneity, with $I^{2}$ value of $27 \%$; and microsurgery group demonstrated minimal heterogeneity, with $I^{2}$ value of $1 \%$. Aggregated data found that patients treated by microsurgery foraminotomy have lower blood loss by $100.1 \mathrm{ml}$ (open: $149.5 \mathrm{ml}$, microsurgery: $49.4 \mathrm{ml}, n=1257$ ), shorter surgical time by 24.9 minutes (open 88.7 minutes, microsurgery 63.8 minutes, $n=1423$ ), and shorter hospital stay by 3.0 days (open 4.1 days, microsurgery 1.1 days, $n=1350$ ), compared with
\end{abstract}

Zhenming $\mathrm{Hu}$

spinecenterhu@163.com

1 Department of Orthopaedics, the First Affiliated Hospital of Chongqing Medical University, Chongqing, China

2 Department of Orthopaedics, Suining Central Hospital, Sichuan, China patients treated by open cervical foraminotomy. The pooled clinical success rate was $89.7 \%$ [confidence interval (CI) 87.7-91.6) in the open group versus $92.5 \%$ (CI 89.9-95.1) in the microsurgery group, with no statistical difference $(p=0.095)$. Overall complication rates were not statistically significant between groups $(p=0.757)$. The incidence of dural tears was $1.07 \%($ $12 / 1121)$ in patients undergoing microsurgery versus $0.27 \%$ $(2 / 745)$ for open surgery $(p=0.091)$. The incidence of infection was $0.54 \%(6 / 1121)$ in patients undergoing microsurgery versus $0.40 \%(3 / 745)$ for open surgery $(p=0.949)$. The incidence of root injury was $0.80 \%(9 / 1121)$ in patients undergoing microsurgery versus $1.48 \%(11 / 745)$ for open surgery $(p=0.166)$. Revision surgery occurred in $2.32 \%$ (27/1163) in the microsurgery group versus $3.35 \%$ (28/835) for traditional surgery, with no statistical difference $(p=0.164)$. Pooled reduction in visual analogue scale for the arm (VASA) was 75.0 \% (CI 66.0-84.0) in the open group and $87.1 \%$ (CI:76.7, 97.5) in the microsurgery group, with no statistical difference $(p=0.065)$. Pooled reduction in VAS of the neck (VASN) was $66.2 \%$ (CI:52.2, 80.2) in the open group and $68.1 \%$ (CI:36.4, 99.8) in the microsurgery group, with no statistical difference $(p=0.894)$. Pooled improvement in neurological function was $55.3 \%$ (CI:18.6, 91.9) in the open group and $64.9 \%(\mathrm{CI}: 34.6,95.2)$ in the microsurgery group, with no statistical difference $(p=0.576)$.

Conclusions Although advantages of cervical microsurgery are less blood loss and shorter surgical time and hospital stay over the standard open technique, there is no significant difference in clinical success rate, complication rate, reduction of arm and neck pain and improvement of neurological function between microsurgery and open cervical foraminotomy.

Keywords Open cervical foraminotomy $\cdot$ Minimally invasive spinal surgery $\cdot$ Microendoscopic foraminotomy $\cdot$ Clinical outcomes $\cdot$ Complications $\cdot$ Systematic review 


\section{Introduction}

Minimally invasive spinal surgery (MISS) represented by microendoscopic discectomy (MED) has been developing rapidly since the 1980 s. Percutaneous technology, endoscopic technology and minimal-access technology are three kinds of commonly used minimally invasive surgery, the application range of which extends from the thoracolumbar region to the cervical spine. Further, due to extraordinary advances in microsurgery techniques, allowing care and treatment of cervical radiculopathy, microsurgery of the cervical spine has become a focus of research. An increasing number of studies reported little trauma, reduced blood loss, shorter hospital stays faster recovery times and safety and reliability as advantages via microendoscopic foraminotomy [1-5].

There is no doubt that the minimally invasive concept is an important direction for development of the cervical spine. However, almost all scholars agree that indications for microsurgery should be aimed at a small range of soft lesions, such as single- or double-segments intervertebral disc pathological changes; large or complex pathological changes, such as cervical ossification of the posterior longitudinal ligament are not suitable for microsurgery [6-8]. Another problem that cannot be ignored is that microsurgery techniques often deal with part of the pathological disc, which is not removed completely, and may result in complications, such as intervertebral disc degeneration or infection [9]. Only a few high-level, evidence-based literature reports are available regarding the clinical effect from different angles between microsurgery and open surgery [10]; there remains considerable debate about the use of open or microsurgery techniques for treating cervical radiculopathy. The purpose of this article was to systematically review clinical outcomes of microendoscopic foraminotomy compared with the traditional open cervical foraminotomy.

\section{Materials and methods}

\section{Literature review}

Our systematic review conforms to recommendations in the Preferred Reporting Items for Systematic Reviews and Meta-Analyses (PRISMA) statement [11]. We conducted a systematic literature search in PubMed, MEDLINE (OVID interface) between January 1990 and December 2015. Procedures included in this review were cervical foraminotomy or laminoforaminotomy for open methods or microsurgery approaches (including cervical endoscopic, full endoscopic, microendoscopic and microscopic approaches). Inclusion criteria in were English language, adult only, subaxial spine, radiculopathy treated with a cervical foraminotomy and minimum of 15 patients for a given study with an available full text. Studies were excluded if they involved interbody fusion, revision surgery, trauma, intervertebral disc replacement, vertebral body replacement or tumour cases.

The abstracts of each article were reviewed by two independent authors to assess for inclusion in the review. All authors then jointly reviewed full texts and extracted the following data: study design, patient demographics, surgical procedures performed, spine segment treated, surgical results, reported complications and follow-up results. Discrepanceis were resolved by consensus. Level of evidence ratings was assigned to each article independently using criteria of the Centre for Evidence-Based Medicine (CEBM) Levels of Evidence 2.1. http://www.cebm.net/index.aspx? $=5653$.

\section{Statistical analysis}

The quality of included studies was assessed based on the CEBM, and statistical heterogeneity between studies was evaluated with the $I^{2}$-statistic [results of clinical success were performed by calculating effect indicators and standard errors (SE) based on single rate using the RevMan software, version 5.2); $I^{2}$ values $<25 \%$ indicate consistent results and homogeneous studies in the same group. The data extracted were number of patients; patient age; time of follow-up; blood loss (blood loss that could not be measured was assumed to be $5 \mathrm{ml}$ ), surgical time, hospital stay (discharged the same day: 0.5 patient days; the next day: 1.0 patient days); reduction of arm and neck pain [visual analogue scale of the arm (VASA)/ visual analogue scale of the neck (VASN), preoperative VAS,

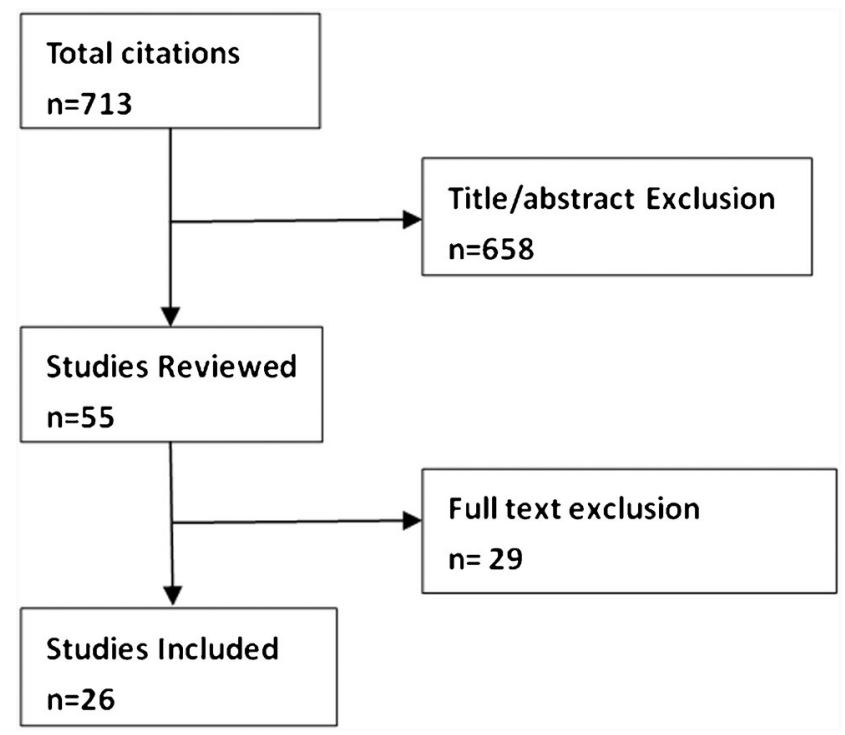

Fig. 1 Systematic review process to select studies 
Table 1 Summary of studies in the open group

\begin{tabular}{llllll}
\hline Study & $\begin{array}{l}\text { Level of } \\
\text { evidence }\end{array}$ & $\begin{array}{l}\text { No. } \\
\text { patients }\end{array}$ & $\begin{array}{l}\text { Age } \\
\text { (years) }\end{array}$ & $\begin{array}{l}\text { Follow-up } \\
\text { (months) }\end{array}$ & Procedure \\
\hline Kang et al. [2] 2014 & 3 & 117 & 52.1 & 36.1 & PCF \\
Park et al. [3] 2013 & 4 & 50 & 51 & 105.6 & AF \\
Jho et al. [35] 2002 & 4 & 104 & 46 & 36 & AF \\
Kim et al. [29] 2009 & 1 & 19 & 54.1 & 34.2 & PCF \\
Cornelius et al. [36] 2007 & 4 & 40 & 50.6 & 51.6 & AF \\
Holly et al [30] 2007 & 4 & 21 & 51 & 23 & PCF \\
Witzmann et al [37] 2000 & 4 & 57 & 43.4 & 37.2 & PCF \\
Chang et al. [31] 2011 & 4 & 34 & 53.6 & 18 & PCF \\
Korinth et al. [32] 2006 & 3 & 168 & 46.9 & 72.1 & PCF \\
Skovrlj et al. [38],2014 & 3 & 70 & 50.5 & 26 & PCF \\
Winder et al. [12] 2011 & 3 & 65 & 51.2 & NR & PCF \\
Choi et al. [42] 2007 & 3 & 20 & 48.7 & 16.7 & AF \\
Kotil et al. [39] 2007 & 3 & 25 & 51.8 & 25.3 & AF \\
Saringer et al. [40] 2002 & 4 & 34 & 43.8 & 8.2 & AF \\
Balasubramanian et al. [41] 2008 & 4 & 34 & 48.1 & 5.6 & AF \\
Grieve et al. [33] 2000 & 4 & 62 & 52 & 40 & PCF \\
\hline
\end{tabular}

$A F$ anterior foraminotomy, $P C F$ posterior cervical foraminotomy, $N R$ not reported postoperative VAS/preoperative VAS)]; improvement of neurological function based on the Neck Disabilitv Index (NDI) or the North American Spine Society Instrument Score (NASS); post-operative score; pre-operative score/preoperative score; complications, clinical success rate (excellent/good equaling success and fair/poor equaling failure based on the Odom or Prolo criteria or complete remission was reported); and repeated surgery rate. Data were summarized, calculated and compared.

Comparison between groups was performed using the $t$ test for analysis of metric scaled data and the ci-square test for analysis of categorical data (SPSS software, version 18.0). Confidence intervals were reported at $95 \%$ levels. $P$ values $<0.05$ were considered statistically significant.

\section{Results}

\section{Study selection}

An initial search found 713 papers published between January 1990 and December 2015. Among them, 658 were excluded

Table 2 Summary of studies included in the microsurgery group

\begin{tabular}{|c|c|c|c|c|c|}
\hline Study & $\begin{array}{l}\text { Level of } \\
\text { evidence }\end{array}$ & No. patients & Age (years) & $\begin{array}{l}\text { Follow-up time } \\
\text { (months) }\end{array}$ & Procedure \\
\hline Ruetten S et al. [5],2008 & 1 & 100 & 43 & 24 & Full endoscopic \\
\hline Winder MJ et al. [12],2011 & 3 & 42 & 50.7 & NR & Microscopic \\
\hline Kim CH et al. [13],2015 & 3 & 44 & 50.5 & 23 & Microscopic \\
\hline Branch BC et al. [14],2015 & 4 & 463 & 49.6 & 14 & Microscopic \\
\hline Deukmedjian AJ et al. [15],2013 & 4 & 66 & 40 & 3 & Full endoscopic \\
\hline Minamide A et al. [34],2010 & 4 & 51 & 62.9 & 20.3 & Microendoscopic \\
\hline Fessler RG et al. [16],2002 & 2 & 25 & 49.6 & 4.6 & Microendoscopic \\
\hline Hilton Jr. et al. [17],2007 & 4 & 222 & 49 & 26 & Microscopic \\
\hline Yadav YR et al. [18],2014 & 4 & 50 & 55.4 & 19 & Endoscopic \\
\hline Ruetten S et al. [19],2007 & 4 & 100 & 44 & 24 & Full endoscopic \\
\hline
\end{tabular}

$N R$ not reported 
Fig. 2 Logit event rate by study in the open group

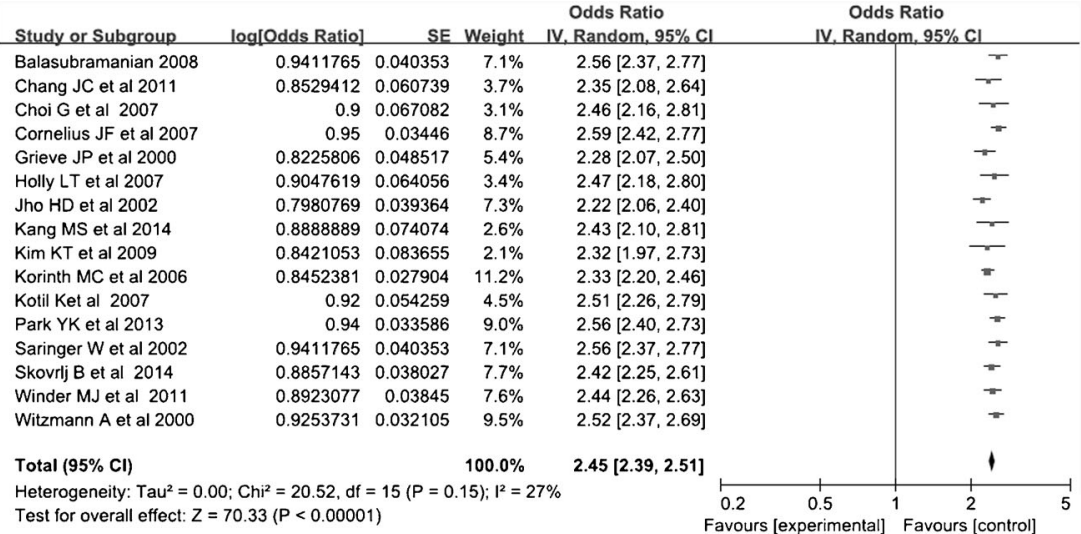

because they were not full-text studies. The remaining 55 citations received a full-text review. Studies that contained case reports, procedures related to the atlantoaxial junction, discectomy, nucleotomy and laminoforaminotomy or foraminotomy with laminoplasty were excluded. The remaining 26 publications were used in this systematic review (Fig. 1).

There was one randomised controlled trial, two prospectively followed cohorts and 13 retrospective case series in the open group compared with one randomised controlled trial, two prospectively followed cohorts and seven retrospective case series in the microsurgery group. Descriptive information for each study is given in Tables 1 and 2.

Three publications were excluded because they did not reported the clinical success rate in the microsurgery group [20-22] compared with six publications in the open group [23-27], and one was excluded because it reported patients younger than 15 years $(n=13)$ in the open group [28].

\section{Study heterogeneity}

Statistical heterogeneity of the studies was performed by calculating effect indicators and standard errors (SE) based on clinical success rate. Statistical heterogeneity between studies was evaluated with the $I^{2}$ statistic. A Forest plot of the logit event rates demonstrated minimal to moderate heterogeneity, with an $I^{2}$ value of $27 \%$ in the open group. There was also minimal heterogeneity in the microsurgery group, with $I^{2}$ value of $1 \%$ (Figs. 2 and 3 ).

\section{Blood loss, surgical time and hospital stay}

Seven studies reported one or more peri-operative outcomes related to blood loss, surgical time and hospital stay in the open group compared with ten in the microsurgery group (Tables 3 and 4). Data aggregated from these reports found that patients treated by microsurgery foraminotomy have lower blood loss by $100.1 \mathrm{ml}$ (open $149.5 \mathrm{ml}$, microsurgery $49.4 \mathrm{ml}, n=1257$ ), shorter surgical time by 24.9 minutes (open 88.7 minutes, microsurgery 63.8 minutes, $n=1423$ ) and shorter hospital stay by 3 days (open 4.1 days, microsurgery 1.1 days, $n=1350$ ) compared with patients treated by open cervical foraminotomy (Figs. 4, 5 and 6).

\section{Clinical success rate}

Clinical success rates were reported in all studies. The pooled clinical success rate was $89.7 \%$ (CI:87.7, 91.6) in the open group and $92.5 \%(\mathrm{CI}: 89.9,95.1)$ in the microsurgery group (Table 5); the difference was not statistically significant between groups $(p=0.095)$.
Fig. 3 Logit event rate by study in the microsurgery group

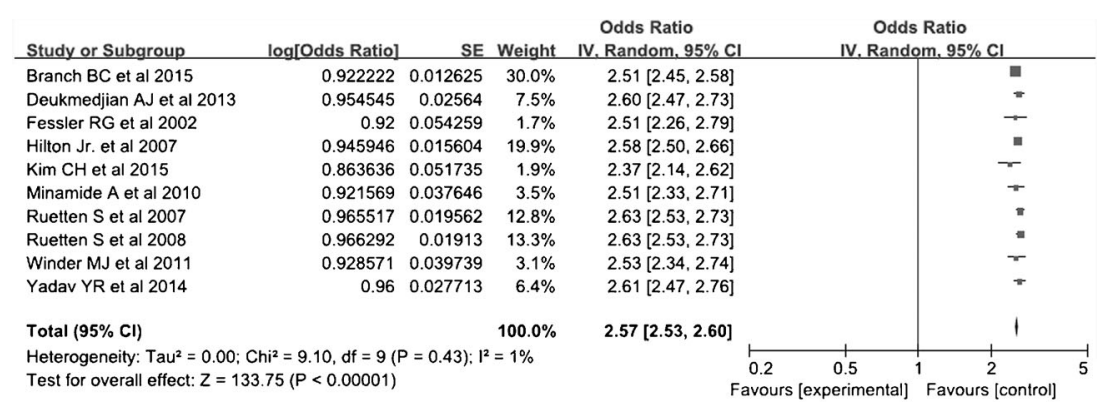


Table 3 Studies reporting blood loss, surgical time and hospital stay from open procedures

\begin{tabular}{lllll}
\hline Study & No. patients & Blood Loss (ml) & Surgical time (min) & Hospital stay (days) \\
\hline Kang et al. [2] 2014 & 18 & 169.7 & 95.7 & 9.5 \\
Kim KT et al. [29],2009 & 19 & NR & 76.5 & 6.7 \\
Holly LT et al. [30],2007 & 21 & 35 & NR & 0.7 \\
Chang JC et al. [31],2011 & 34 & 50 & 37 & 3 \\
Korinth MC et al. [32], 2006 & 168 & NR & 94.1 & 4.5 \\
Winder MJ et al. [12],2011 & 65 & 233 & 103.3 & 2.4 \\
Grieve JP et al. [33],2000 & 62 & NR & NR & 4 \\
\hline
\end{tabular}

$N R$ not reported

\section{Complications}

The pooled complications rate was $3.35 \%(28 / 835)$ in the open group and $3.61 \%(42 / 1163)$ in the microsurgery group. The difference in complication rate was not statistically significant between groups $(p=0.757$, Pearson chisquare). The most common complications in either group were dural tears, nerve root injury and infection. Dural tears were an infrequent occurrence in both groups. Pooled dural tear rate amongst all microsurgery procedures in our review was $1.07 \%(12 / 1121)$. Traditional open surgery had an overall $0.27 \%(2 / 745)$ incidence $(p=0.091$, continuity correction). Continuity correction yielded $p=0.091$, indicating weak evidence approaching significance for difference between microsurgery and open procedures. Overall rates of infection were low, only occurring in $0.54 \%(6 / 1121)$ in the microsurgery group; the traditional open surgery had a $0.40 \%(3 / 745)$ incidence ( $p=0.949$, continuity correction). Continuity correction yielded $p=0.949$, indicating no significant difference in infection between microsurgery and open procedures. Nerve root injury occurred in $0.80 \%(9 / 1121)$ of trials in the microsurgery group: Traditional open surgery had a $1.48 \%(11 / 745)$ rate $(p=0.166$, Pearson chi- square). Pearson chi-square yield $p=0.166$, indicating no significant difference between groups.

\section{Revision surgery}

Revision surgery occurred in $2.32 \%$ (27/1163) of trials in the microsurgery group, and traditional open surgery had a rate of $3.35 \%(28 / 835)(p=0.164$, Pearson chi-square). Pearson chisquare yielded $p=0.164$, indicating no significant difference in revision surgery between microsurgery and open procedures.

\section{Reduction of VASA/VASN}

Ten publications reported post-operative outcomes related to the reduction of arm and/or neck pain (VASA/VASN) in the open compared with six in the microsurgery group. Pooled VASA reduction was $75.0 \%$ (CI:66..0, 84.0) in the open group and $87.1 \%(\mathrm{CI}: 76.7,97.5)$ in the microsurgery group (Table 6); the difference was not statistically significant between groups ( $p=0.065$ ).

Pooled reduction of VASN was $66.2 \%$ (CI:52.2, 80.2) in the open and $68.1 \%(\mathrm{CI}: 36.4,99.8)$ in the microsurgery group
Table 4 Studies reporting blood loss, surgical time and hospital stay for microsurgery group

\begin{tabular}{lllll}
\hline Study & No. & Blood Loss (ml) & Surgical time (min) & Hospital stay (days) \\
\hline Ruetten S et al. [5],2008 & 100 & 5 & 28 & NR \\
Winder MJ et al. [12],2011 & 42 & 96 & 100.7 & 1.12 \\
Kim CH et al. [13],2015 & 44 & NR & NR & 1 \\
Branch BC et al. [14],2015 & 463 & 59.5 & 59.7 & 0.51 \\
Deukmedjian AJ et al. [15],2013 & 66 & 5 & 57 & 0.5 \\
Minamide A et al. [34],2010 & 51 & 32.6 & 130.8 & 8.6 \\
Fessler RG et al. [16],2002 & 25 & 138 & 115 & 0.83 \\
Hilton Jr. et al. [17],2007 & 222 & 71 & 63 & 0.48 \\
Yadav YR et al. [18],2014 & 50 & 30 & 135 & 2.2 \\
Ruetten S et al. [19],2007 & 100 & 5 & 27 & NR \\
\hline
\end{tabular}

$N R$ not reported 


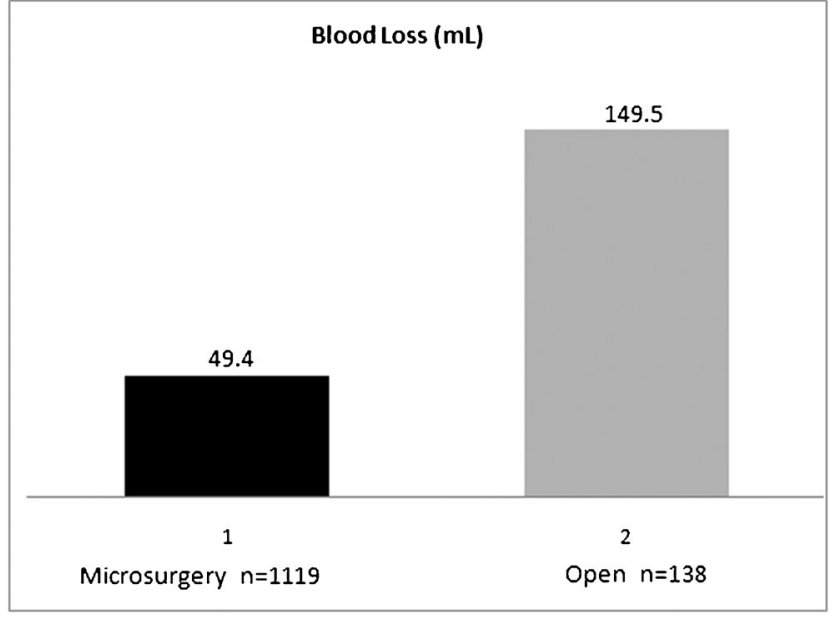

Fig. 4 Comparison of blood loss between microsurgery and open groups

(Table 6). The difference in VASN reduction was not statistically significant $(p=0.894)$.

\section{Improvement of neurological function}

Five publications reported post-operative outcomes related to improvement in neurological function based on the NDI or the NASS in either group. Pooled improvement of neurological function was $55.3 \%$ (CI:18.6, 91.9) in the open and $64.9 \%$ (CI:34.6, 95.2) in the microsurgery group. The difference in improvement of neurological function was not statistically significant between groups $(p=0.576)$ (Table 6).

\section{Discussion}

Cervical foraminotomy is an effective treatment for symptomatic cervical radiculopathy. Though the traditional cervical

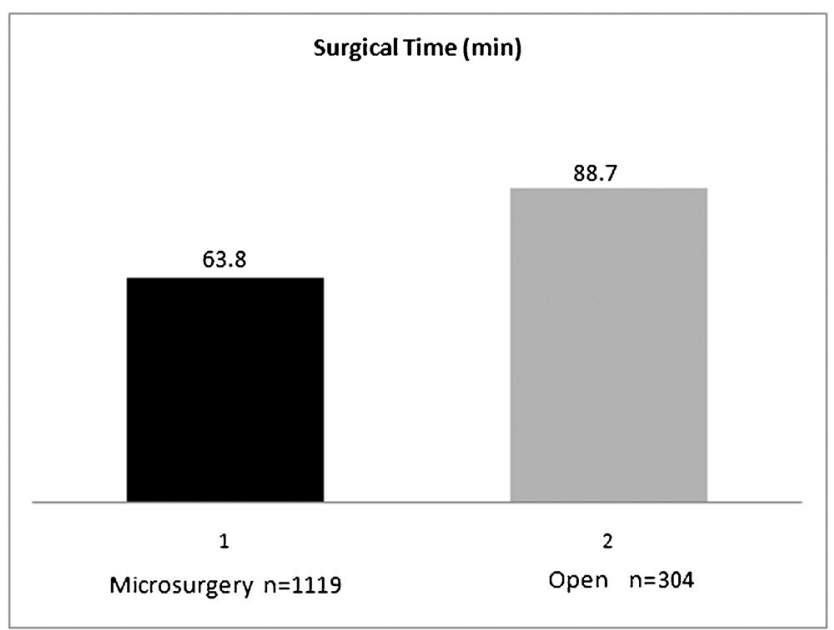

Fig. 5 Comparison of surgical time between microsurgery and open groups

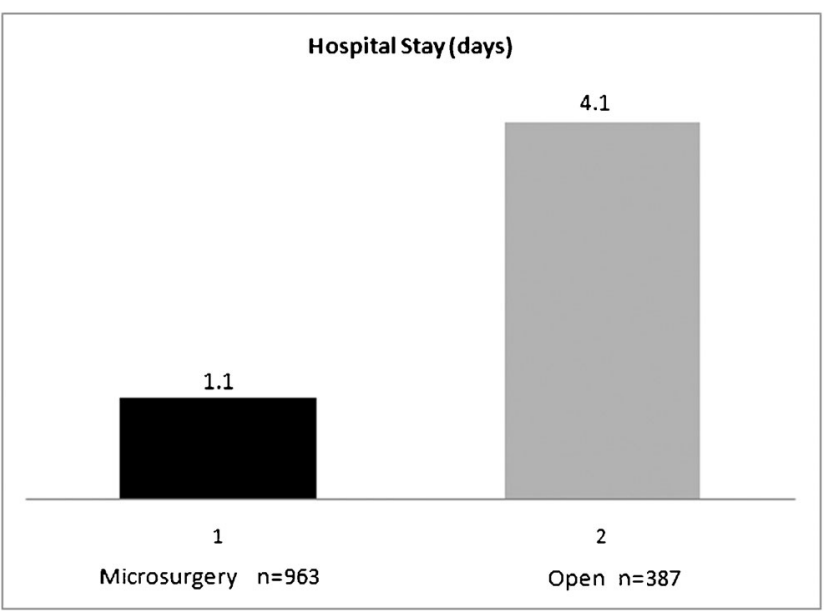

Fig. 6 Comparison of hospital stay between microsurgery and open groups

open foraminotomy is a well-established technique for treating cervical radiculopathy, endoscopic surgical techniques, as an alternative to standard open approaches, change with each passing day, with reported outcomes equal to or better than those seen with traditional cervical open foraminotomy. The decision regarding approach and surgery type is based on patient- and surgeon-specific considerations. This systematic review was performed based on the singleeffect indicator of clinical success rate. We identified 26 publications that reported peri-operative outcomes, including clinical success rate, from open $(n=16)$ and microendoscopic $(n=10)$ procedures. In the open group, there was minimal to moderate heterogeneity among studies, with an $I^{2}$ of 27 . The microendoscopic group demonstrated minimal heterogeneity for clinical success, with an $\mathrm{I}^{2}$ value of 1 . It can thus be inferred that results from both open and microendoscopic groups possess good, consistent results, and the results reported are likely close to the true effect. Data aggregated from the published literature including blood loss, surgical time, hospital stay, clinical success rate, complications, reduction in VASA and VASN and improvement in neurological function were analysed and compared between microendoscopic and open procedures. To our knowledge, this is the first systematic review of these procedures.

A recent meta-analysis by Mcanany et al. [43] reported clinical outcomes and success of open foraminotomy versus MIS foraminotomy. They identified 20 studies that met inclusion criteria. The summative clinical success rate was $92.7 \%$ for open and $94.9 \%$ for MIS foraminotomy, which was not statistically significant $(p=0.418)$. In our systematic review, the pooled clinical success rate was $89.7 \%$ in the open group and $92.5 \%$ in the microsurgery group, which is slightly lower than the literature; however, the difference was not statistically significant between groups $(p=0.095)$. A recent systematic review by Clark et al. [44] reported results of open versus 
Table 5 Effect of surgical technique via microsurgery or open cervical foraminotomy and clinical success

\begin{tabular}{|c|c|c|c|c|c|c|c|c|c|}
\hline \multicolumn{5}{|l|}{ Open } & \multicolumn{5}{|c|}{ Microsurgery } \\
\hline \multirow[t]{2}{*}{ Study } & \multirow[t]{2}{*}{ No. } & \multirow[t]{2}{*}{ Clinical success } & \multicolumn{2}{|c|}{$95 \% \mathrm{CI}$} & \multicolumn{2}{|c|}{$95 \% \mathrm{CI}$} & \multirow[t]{2}{*}{ Clinical success } & \multirow[t]{2}{*}{ No. } & \multirow[t]{2}{*}{ Study } \\
\hline & & & Lower & Upper & Upper & Lower & & & \\
\hline Kang MS et al. [2] & $16 / 18$ & 0.889 & 0.665 & 0.986 & 0.993 & 0.910 & 0.966 & $86 / 89$ & Ruetten S et al. [5] \\
\hline Park YK et al. [3] & $47 / 50$ & 0.940 & 0.844 & 0.987 & 0.985 & 0.815 & 0.929 & $39 / 42$ & Winder MJ et al. [12] \\
\hline Jho HD et al. [35] & $83 / 104$ & 0.798 & 0.728 & 0.871 & 0.948 & 0.744 & 0.864 & $38 / 44$ & Kim $\mathrm{CH}$ et al. [13] \\
\hline Kim KT et al. [29] & $16 / 19$ & 0.842 & 0.620 & 0.966 & 0.948 & 0.903 & 0.922 & $415 / 450$ & Branch BC et al. [14] \\
\hline Cornelius JF et al. [36] & $38 / 40$ & 0.950 & 0.838 & 0.994 & 0.990 & 0.880 & 0.955 & $63 / 66$ & Deukmedjian AJ et al. [15] \\
\hline Holly LT et al. [30] & $19 / 21$ & 0.905 & 0.710 & 0.988 & 0.978 & 0.823 & 0.922 & $47 / 51$ & Minamide A et al. [34] \\
\hline Witzmann A et al. [37] & $62 / 67$ & 0.925 & 0.846 & 0.975 & 0.990 & 0.750 & 0.920 & $23 / 25$ & Fessler RG et al. [16] \\
\hline Chang JC et al. [31] & $29 / 34$ & 0.853 & 0.706 & 0.951 & 0.892 & 0.799 & 0.847 & $188 / 222$ & Hilton Jr. et al. [17] \\
\hline Korinth MC et al. [32] & $142 / 168$ & 0.845 & 0.791 & 0.896 & 0.995 & 0.869 & 0.960 & $48 / 50$ & Yadav YR et al. [18] \\
\hline Skovrlj B et al. [38] & $62 / 70$ & 0.886 & 0.802 & 0.950 & 0.993 & 0.908 & 0.966 & $84 / 87$ & Ruetten S et al. [19] \\
\hline Winder MJ et al. [12] & $58 / 65$ & 0.892 & 0.805 & 0.956 & & & & & \\
\hline Choi $\mathrm{G}$ et al. [30] & $18 / 20$ & 0.900 & 0.693 & 0.988 & & & & & \\
\hline Kotil Ket al [39] & $23 / 25$ & 0.920 & 0.750 & 0.990 & & & & & \\
\hline Saringer W et al. [40] & $32 / 34$ & 0.941 & 0.812 & 0.993 & & & & & \\
\hline Balasubramanian et al.[41] & $32 / 34$ & 0.941 & 0.812 & 0.993 & & & & & \\
\hline Grieve JP et al. [33] & $51 / 62$ & 0.823 & 0.724 & 0.908 & & & & & \\
\hline Choi G et al. [30] & $18 / 20$ & 0.900 & 0.693 & 0.988 & & & & & \\
\hline
\end{tabular}

$C i$ confidence interval

percutaneous foraminotomy, identifying 19 studies that met inclusion criteria. Their systematic review reported that patients undergoing percutaneous cervical foraminotomy have lower blood loss, shorter surgical time and shorter hospital stay compared with patients undergoing open procedures. By comparison, our data aggregated in this systematic review

Table 6 Reduction of visual analogue scale for the arm (VASA) and neck (VASN) and improvement in neurological function via microsurgery or open cervical foraminotomy

\begin{tabular}{|c|c|c|c|c|c|c|c|}
\hline \multicolumn{4}{|l|}{ Open } & \multicolumn{4}{|l|}{ Microsurgery } \\
\hline Study & $\begin{array}{l}\text { Reduction } \\
\text { of VASN }\end{array}$ & $\begin{array}{l}\text { Reduction } \\
\text { of VASA }\end{array}$ & $\begin{array}{l}\text { Improvement } \\
\text { of neurological } \\
\text { function }\end{array}$ & $\begin{array}{l}\text { Improvement } \\
\text { of neurological } \\
\text { function }\end{array}$ & $\begin{array}{l}\text { Reduction } \\
\text { of VASA }\end{array}$ & $\begin{array}{l}\text { Reduction } \\
\text { of VASN }\end{array}$ & Study \\
\hline Kang MS et al. [2] & $56.5 \%$ & $48.5 \%$ & NR & $50 \%$ & $91.7 \%$ & $5.9 \%$ & Ruetten S et al. [5] \\
\hline Park YK et al. [3] & $53.7 \%$ & $72.7 \%$ & $57.7 \%$ & $86.3 \%$ & $87 \%$ & $86 \%$ & Kim CH et al. [13] \\
\hline Jho HD et al. [35] & $66.9 \%$ & $66.9 \%$ & $13.5 \%$ & NR & $94.3 \%$ & $94.3 \%$ & Deukmedjian et al. [15] \\
\hline Kim KT et al. [29] & $76.7 \%$ & $78.4 \%$ & NR & NR & $67.4 \%$ & $67.4 \%$ & Minamide A et al. [34] \\
\hline Witzmann A et al. [37] & $71.6 \%$ & $71.6 \%$ & NR & NR & $92 \%$ & $87 \%$ & Fessler RG et al. [16] \\
\hline Chang JC et al. [31] & $20.5 \%$ & $68.5 \%$ & NR & $64.6 \%$ & NR & NR & Yadav YR et al. [18] \\
\hline Skovrlj B et al. [38] & $83.3 \%$ & $83.3 \%$ & $68.9 \%$ & $58.8 \%$ & $90.1 \%$ & $-20 \%$ & Ruetten S et al. [19] \\
\hline Choi $\mathrm{G}$ et al. [42] & $65 \%$ & $92 \%$ & $92.8 \%$ & & & & \\
\hline Kotil K et al. [39] & $89.9 \%$ & $89.9 \%$ & NR & & & & \\
\hline $\begin{array}{c}\text { Balasubramanian } \\
\text { et al. [41] }\end{array}$ & $77.8 \%$ & $77.8 \%$ & $43.5 \%$ & & & & \\
\hline
\end{tabular}

NR not reported 
found that patients undergoing microsurgery procedures have lower blood loss by $100.1 \mathrm{ml}$, shorter surgical time by $24.9 \mathrm{mi}-$ nutes and shorter hospital stay by 3.0 days. Similar results have been achieved, but the authors did not look specifically at the outcomes of clinical success, complications, reduction of VASA and VASN and improvement of neurological function. This difference accounts for the different number of studies included in our systematic review.

Specifically, the quality of available studies comparing complications and revision surgery between microendoscopic and open spinal surgeries limits this systematic review. Twelve of our studies were small, with 50 or fewer participants in each study arm, and four of our studies reported on the overall follow-up time $<12$ months. Most studies were cohorts, which can introduce selection bias, since it is possible that more complex cases prone to complications and revision surgery underwent either procedure. For example, Fessler et al. [16] reported that 25 patients treated with microendoscopic foraminotomy had no symptomatic recurrences of disc herniations or foraminal stenosis at the operated level within 4.6 months' follow-up. In order to accurately determine the rate of complications and revision surgery, large prospective trials are needed that account for both surgeon experience and patient comorbidity through random allocation or statistical controlling.

Meanwhile, we are aware that fewer results correlated with pain relief in microsurgery or open foraminotomy have been published. In addition, few of these studies take into account the improvement of neurological function. To analyse more fully, we included results on functional recovery in our systematic review. Particularly worth mentioning is the randomised clinical trial conducted by Ruetten et al. [10], which reported significant reduction in radicular pain symptoms $(P<0.001)$ and the improvement in neurological function by $50 \%$ based on the NASS score in the full-endoscopic group. However, reduction of neck pain was only $5.9 \%$, and more advancing degeneration in the disc (24\%) may be the reason for little reduction in neck pain in the full-endoscopic group.

This study is limited by the paucity of good, randomised controlled studies, and the heterogeneous nature of reported outcomes made strict meta-analysis impossible. It is important that more structured and thorough trials be designed to clarify the risks and benefits associated with each of these procedures.

Microsurgery has reduced blood loss and shorter surgical time and hospital stay as advantages over the standard open technique. However, there is no significant difference in clinical success rate, complication rate, reduction of arm and neck pain and improvement of neurological function between microsurgery and open cervical foraminotomy. Patients with symptomatic cervical radiculopathy can be effectively managed with either microsurgery or traditional open foraminotomy. The decision on approach and surgery type are based on both patient- and surgeon-specific considerations.

Open Access This article is distributed under the terms of the Creative Commons Attribution 4.0 International License (http:// creativecommons.org/licenses/by/4.0/), which permits unrestricted use, distribution, and reproduction in any medium, provided you give appropriate credit to the original author(s) and the source, provide a link to the Creative Commons license, and indicate if changes were made.

\section{References}

1. Fontanella A (1999) Endoscopic microsurgery in herniated cervical discs. Neurol Res 21(1):31-38

2. Kang MS, Choi KC, Lee CD et al (2014) Effective cervical decompression by the posterior cervical foraminotomy without discectomy. J Spinal Disord Tech 27(5):271-276. doi:10.1097/ BSD.0b013e3182a35707

3. Park YK, Moon HJ, Kwon TH et al (2013) Long-term outcomes following anterior foraminotomy for one- or two-level cervical radiculopathy. Eur Spine J 22(7):1489-1496. doi:10.1007/s00586013-2712-x

4. Roh SW, Kim DH, Cardoso AC et al (2000) Endoscopic foraminotomy using MED system in cadaveric specimens. Spine (Phila Pa 1976) 25(2):260-264

5. Ruetten S, Komp M, Merk H et al (2008) Full-endoscopic cervical posterior foraminotomy for the operation of lateral disc herniations using 5.9-mm endoscopes: a prospective, randomized, controlled study. Spine (Phila Pa 1976) 33(9):940-948. doi:10.1097/BRS. 0b013e31816c8b67

6. Yang JS, Chu L, Chen L et al (2014) Anterior or posterior approach of full-endoscopic cervical discectomy for cervical intervertebral disc herniation? a comparative cohort study. Spine 39(21):17431750. doi:10.1097/BRS.0000000000000508

7. Yao N, Wang C, Wang W et al (2011) Full-endoscopic technique for anterior cervical discectomy and interbody fusion: 5-year follow-up results of 67 cases. Eur Spine J 20(6):899-904. doi:10.1007/ s00586-010-1642-0

8. Zaidi HA, Montoure AJ, Dickman CA (2015) Surgical and clinical efficacy of sacroiliac joint fusion: a systematic review of the literature. J Neurosurg Spine 23(1):59-66. doi:10.3171/2014.10

9. Ross DA (2014) Complications of minimally invasive, tubular access surgery for cervical, thoracic, and lumbar surgery. Minim Invasive Surg 451637. doi: 10.1155/2014/451637

10. Franke J, Greiner-Perth R, Boehm H et al (2009) Comparison of a minimally invasive procedure versus standard microscopic discotomy: a prospective randomised controlled clinical trial. Eur Spine J 18(7):992-1000. doi:10.1007/s00586-009-0964-2

11. Moher D, Liberati A, Tetzlaff J, Altman DG, The PG (2009) Preferred reporting items for systematic reviews and meta-analyses: the PRISMA statement. PRISMA Statement PLoS Med 6: e1000097

12. Winder MJ, Thomas KC (2011) Minimally invasive versus open approach for cervical laminoforaminotomy. Can J Neurol Sci 38(2): 262-267

13. Kim CH, Kim KT, Chung CK et al (2015) Minimally invasive cervical foraminotomy and diskectomy for laterally located soft disk herniation. Eur Spine J 24(12):3005-3012. doi:10.1007/ s00586-015-4198-1

14. Branch BC, Hilton DL Jr, Watts C (2015) Minimally invasive tubular access for posterior cervical foraminotomy. Surg Neurol Int 6: 81. doi:10.4103/2152-7806.157308 
15. Deukmedjian AJ, Jason Cutright ST, Augusto Cianciabella PC et al (2013) Deuk Laser Disc Repair ${ }^{\circledR}$ is a safe and effective treatment for symptomatic cervical disc disease. Surg Neurol Int 4:68. doi:10. 4103/2152-7806.112610

16. Fessler RG, Khoo LT (2002) Minimally invasive cervical microendoscopic foraminotomy: an initial clinical experience. Neurosurgery 51(5 Suppl):S37-S45

17. Hilton DL Jr (2007) Minimally invasive tubular access for posterior cervical foraminotomy with three-dimensional microscopic visualization and localization with anterior/posterior imaging. Spine J 7(2):154-158

18. Yadav YR, Parihar V, Ratre S et al (2014) Endoscopic decompression of cervical spondylotic myelopathy using posterior approch. Neurol India 62(6):640-645. doi:10.4103/0028-3886.149388

19. Ruetten S, Komp M, Merk H et al (2007) A new full-endoscopic technique for cervical posterior foraminotomy in the treatment of lateral disc herniations using 6.9-mm endoscopes: prospective 2year results of 87 patients. Minim Invasive Neurosurg 50(4):219-226

20. Lawton CD, Smith ZA, Lam SK et al (2014) Clinical outcomes of microendoscopic foraminotomy and decompression in the cervical spine. World Neurosurg 81(2):422-427. doi:10. 1016/j.wneu.2012.12.008

21. Liu GM, Wang YJ, Wang DS et al (2013) Comparison of one-level microendoscopy laminoforaminotomy and cervical arthroplasty in cervical spondylotic radiculopathy: a minimum 2-year follow-up study. J Orthop Surg Res 8:48. doi:10.1186/1749-799X-8-48

22. Haufe SM, Mork AR, Pyne MA et al (2009) Endoscopic laminoforaminoplasty success rates for treatment of foraminal spinal stenosis: report on sixty-four cases. Int J Med Sci 6(2):102-105

23. Church EW, Halpern CH, Faught RW et al (2014) Cervical laminoforaminotomy for radiculopathy: symptomatic and functional outcomes in a large cohort with long-term followup. Surg Neurol Int 5(Suppl 15):S536-S543. doi:10.4103/ 2152-7806.148029

24. Zeidman SM, Ducker TB (1993) Posterior cervical laminoforaminotomy for radiculopathy: review of 172 cases. Neurosurgery 33(3):356-362

25. Terai H, Suzuki A, Toyoda $H$ et al (2014) Tandem keyhole foraminotomy in the treatment of cervical radiculopathy: retrospective review of 35 cases. J Orthop Surg Res 9:38. doi:10.1186/1749799X-9-38

26. Kwon YJ (2014) Long-term clinical and radiologic outcomes of minimally invasive posterior cervical foraminotomy. J Korean Neurosurg Soc 56(3):224-229. doi:10.3340/jkns.2014.56.3.224

27. Umebayashi D, Hara M, Nakajima Y et al (2013) Transvertebral anterior cervical foraminotomy midterm outcomes of clinical and radiological assessments including the finite element method. Eur Spine J 22(12):2884-2890. doi:10.1007/s00586-013-2974-3

28. Lee JY, Löhr M, Impekoven P et al (2006) Small keyhole transuncal foraminotomy for unilateral cervical radiculopathy. Acta Neurochir (Wien) 148(9):951-958

29. Kim KT, Kim YB (2009) Comparison between open procedure and tubular retractor assisted procedure for cervical radiculopathy: results of a randomized controlled study. J Korean Med Sci 24(4): 649-653. doi:10.3346/jkms.2009.24.4.649

30. Holly LT, Moftakhar P, Khoo LT et al (2007) Minimally invasive 2Llevel posterior cervical foraminotomy: preliminary clinical results. J Spinal Disord Tech 20(1):20-24

31. Chang JC, Park HK, Choi SK (2011) Posterior Cervical inclinatory foraminotomy for spondylotic radiculopathy preliminary. J Korean Neurosurg Soc 49(5):308-313. doi:10.3340/jkns.2011.49.5.308

32. Korinth MC, Krüger A, Oertel MF et al (2006) Posterior foraminotomy or anterior discectomy with polymethyl methacrylate interbody stabilization for cervical soft disc disease: results in 292 patients with monoradiculopathy. Spine (Phila Pa 1976) 31(11):1207-1214, discussion 1215-6

33. Grieve JP, Kitchen ND, Moore AJ et al (2000) Results of posterior cervical foraminotomy for treatment of cervical spondylitic radiculopathy. Br J Neurosurg 14(1):40-43

34. Minamide A, Yoshida M, Yamada H et al (2010) Clinical outcomes of microendoscopic decompression surgery for cervical myelopathy. Eur Spine J 19(3):487-493. doi:10.1007/s00586-009-1233-0

35. Jho HD, Kim WK, Kim MH (2002) Anterior Microforaminotomy for treatment of cervical radiculopathy: part 1-disc-preserving "functional cervical disc surgery". Neurosurgery 51(5 Suppl): S46-S53

36. Cornelius JF, Bruneau M, George B (2007) Microsurgical cervical nerve root decompression via an anterolateral approach:clinical outcome of patients treated for spondylotic radiculopathy. Neurosurgery 61(5):972-980, discussion 980

37. Witzmann A, Hejazi N, Krasznai L (2000) Posterior cervical foraminotomy. a follow-up study of 67 surgically treated patients with compressive radiculopathy. Neurosurg Rev 23(4):213-217

38. Skovrlj B, Gologorsky Y, Haque R et al (2014) Complications, outcomes, and need for fusion after minimally invasive posterior cervical foraminotomy and microdiscectomy. Spine J 14(10):24052411. doi:10.1016/j.spinee.2014.01.048

39. Kotil K, Bilge T (2008) Prospective study of anterior cervical microforaminotomy for cervical radiculopathy. J Clin Neurosci 15(7):749-756. doi:10.1016/j.jocn.2007.04.013

40. Saringer W, Nöbauer I, Reddy M et al (2002) Microsurgical anterior cervical foraminotomy (uncoforaminotomy) for unilateral radiculopathy- clinical results of a new technique. Acta Neurochir (Wien) 144(7):685-694

41. Balasubramanian C, Price R, Brydon H (2008) Anterior cervical microforaminotomy for cervical radiculopathy - results and review. Minim Invasive Neurosurg 51(5):258-262. doi:10.1055/s-00281082320

42. Choi G, Lee SH, Bhanot A et al (2007) Modified transcorporeal anterior cervical microforaminotomy for cervical radiculopathy- a technical note and early results. Eur Spine J 16(9):1387-1393

43. McAnany SJ, Kim JS, Overley SC et al (2015) A meta-analysis of cervical foraminotomy: open versus minimally-invasive techniques. Spine J 15(5):849-856. doi:10.1016/j.spinee.2015.01.021

44. Clark JG, Abdullah KG, Steinmetz MP et al (2011) Minimally invasive versus open cervical foraminotomy: a systematic review. Global Spine J 1(1):9-14. doi:10.1055/s-0031-1296050 